\title{
EPIDEMIOLÓGIA DOS PACIENTES COM HIPERTENSÃO ARTERIAL CADASTRADOS NA “CASA FAMÍlIA ÁGUA CRISTAL”, BELÉM-PA
}

\author{
Anthony Messias Nascimento SILVA, João Felipe da Costa NUNES, Rodrigo Nery QUINTAS \\ e Thales Braga de Castro MOURA
}

Introdução: A hipertensão arterial (HA) constitui uma doença crônica, altamente prevalente, de alto custo social e grande impacto na morbimortalidade da população mundial e brasileira. Nas Américas, ela afeta 140 milhões de pessoas, entretanto $50 \%$ delas não sabem que são hipertensas. No Brasil a prevalência também é muito alta, variando de 22,3\% a 43,9\%, utilizando-se o critério atual de HA, pressão arterial maior ou igual a 140/90 mmHg. No Estado do Pará, dados do Sistema de Informação de Atenção Básica (SIAB), mostram que em agosto de 2005 havia 98.780 pessoas com hipertensão arterial cadastradas e, dessas 90.247 pessoas acompanhadas. Em Belém, estudos realizados envolvendo 2.287 homens e 2.875 mulheres demonstraram que mais de $70 \%$ dos homens e mulheres não eram hipertensos.

Objetivo: Conhecer o perfil epidemiológico dos pacientes com hipertensão arterial cadastrados na "Casa Família Agua Cristal", em Belém-PA.

Método: Pesquisa transversal realizada por meio de análise de prontuários e protocolos de pesquisa de 100 pacientes hipertensos, na faixa etária acima de 35 anos, cadastrados na "Casa Família Agua Cristal", agosto de 2001 até outubro de 2006. Os dados epidemiológicos foram analisados através do programa BioEstat4 e as variáveis quantitativas pelo teste de normalidade de D'Agostino-Pearson e as Categóricas pelo teste do Qui-Quadrado.

Resultado: A análise dos dados demonstrou que, dentre os pesquisados, $66 \%$ são do gênero feminino contra $34 \%$ do gênero masculino; $11 \%$ se declararam fumantes; $19 \%$ consomem bebidas alcoólicas; $62 \%$ são sedentários; $30 \%$ possuem índice de massa corpórea (IMC) acima de $30 \mathrm{~kg} / \mathrm{m}^{2}$ e $53 \%$ possuem, pelo menos, um antecedente familiar com história da doença.

Considerações finais: a casuística estudada é, em sua maioria mulheres, não fumantes, não consumidores de bebidas alcoólicas, sedentários, apresentando uma prevalência de sobrepeso de $45 \%$, obesidade de $30 \%$ e com confirmação de histórico familiar para a doença. A presença dos fatores de risco remete à importância do implemento de medidas preventivas de alta eficácia por parte do poder público.

DESCRITORES: hipertensão arterial, epidemiologia e fatores de risco.

Universidade do Estado do Pará - UEPA

Casa Família Água Cristal, Belém-PA.

Trabalho apresentado na VI Jornada de Trabalho Científico do Curso de Medicina/UEPA, dezembro/2006 